\title{
Metáfora, metonimia y blending en construcciones ditransitivas del kamaiurá
}

\author{
Metaphor, metonimy and blending in \\ Kamaiurá ditransitive constructions
}

Enrique Huelva Unternbäumen ${ }^{1}$

\begin{abstract}
Resumen
En este trabajo presentamos el análisis conceptual de algunas construcciones gramaticales del kamaiurá, lengua indígena brasileña, perteneciente al grupo étnico-lingüístico tupiguaraní del Alto Xingú. Los casos analizados revelan una alta complejidad semántica resultante, especialmente, de la integración (blending) de la metáfora REALIZAR UNA ACCIÓN ES TRANSMITIR UNA PARTE DEL CUERPO y de la metonimia PARTE DEL CUERPO POR LA ACCIÓN, para conceptuar acciones físicas y perceptuales/cognitivas. A diferencia de muchas lenguas europeas, la combinación de estos dos elementos conceptuales es utilizada en Kamaiurá tanto para la conceptuación de acciones abstractas ("yo te mando mi ojo' = yo me acuerdo de ti) como de acciones concretas ('yo te mando mi brazo' = yo te abrazo). Los datos presentados muestran además la gran importancia cultural que posee en kamaiurá el cuerpo humano como dominio fuente para la configuración de la estructura conceptual codificada por la gramática.
\end{abstract}

Palabras clave: Blending. Metáfora. Metáfora. Metonimia. Cuerpo como espacio fuente.

\begin{abstract}
In this paper, we present a conceptual analysis of certain grammatical constructions in Kamaiurá, a Brazilian indigenous language belonging to the Tupi-Guarani linguisticethnic group of the Upper Xingu. The cases analysed reveal a highly complex semantics, resulting particularly from the blending of the metaphor, TO PERFORM AN ACTION IS TO TRANSMIT A PART OF THE BODY, and the metonymy, A BODY PART FOR THE ACTION, to conceptualize physical and perceptual/cognitive acts. Differently than in many European languages, the combination of these two conceptual elements is utilized in Kamaiurá for the conceptualization of both abstract acts ('I send you my eye' = I remember you) and concrete acts ('I send you my arm' = I embrace you). In addition, the data presented show the great cultural importance of the human body as a source domain for the configuration of the conceptual structure codified in grammar in Kamaiurá.
\end{abstract}

Keywords: Blending. Metaphor. Metonymy. The body as source space.

${ }^{1}$ Universidad de Brasilia - UnB. 


\section{Introducción}

No conocemos verdaderamente la cultura de un pueblo si no conocemos sus metáforas. Y sus metonimias, hay que añadirlo. Nuestro mundo de la vida, el ser y estar en el mundo, nuestras vivencias y experiencias fundamentales, las actividades y acciones que nos relacionan con el medio ambiente y con los otros, las creencias y la espiritualidad sobre las que erguimos la comprensión de lo que somos, poseen, ineludiblemente, una esencia metafórico-metonímica. Del mismo modo, y generalizando lo que acabamos de decir, podemos afirmar que conocer el potencial conceptual del ser humano pasa, sin duda, por la posibilidad de analizar las características que manifiesta el saber metafóricometonímico en las diferentes culturas del mundo y de proponer, a partir de ello, una tipología que recoja, sistemáticamente, tanto la universalidad como la diversidad intercultural de dicho saber. El desafío es afanoso y no hace falta insistir mucho para comprender que estamos todavía dando los primeros pasos de una larga jornada.

El trabajo que presentamos en las próximas páginas pretende ser una contribución a los dos propósitos que acabamos de mencionar. Analizamos un conjunto de metáforas y metonimias del kamaiurá, con el objetivo primero y principal de aproximarnos un poco más a la comprensión de esta lengua y de su cultura, no por último con el deseo expreso de que nuestra labor ayude, en la medida de lo que pueda, a preservarlas y revitalizarlas. En segundo lugar, nuestro estudio proporciona el acceso a metáforas y metonimias de una cultura que hasta el momento no han sido tomadas en consideración en los estudios generales sobre estos fenómenos, ofreciendo de este modo la oportunidad de incluir el saber metafórico-metonímico de este pueblo en el postulado de hipótesis sobre el carácter universal versus particular de la metáfora y la metonimia, fundamentadas aun en un conjunto relativamente pequeño de lenguas, con predominancia de las europeas (Kövecses 2005).

Las estructuras metafórico-metonímicas de las que nos vamos a ocupar están codificadas por construcciones ditransitivas. En Huelva Unternbäumen (2015) mostramos que el polo semántico de construcciones ditransitivas se nos presenta como una multidomain matrix, constituida básicamente por un conjunto (o red) de metáforas conceptuales integradas a través del mecanismo de blending. Las metáforas que participan en la construcción de estos multidomain matrix son, en principio, metáforas que ya existen en nuestra estructura conceptual, independientemente de que sean (o no) usadas como elementos integrantes del polo semántico de construcciones gramaticales. En muchos casos se trata de metáforas primarias (Grady 1997; Lakoff / Johnson 1999: 45-59; Gibbs 2005: 116-118), concebidas como metáforas que poseen una base experiencial directa e independiente. Estas metáforas primarias pueden ser integradas mediante el mecanismo de blending, creando con ello metáforas compuestas (o complejas) que incluyen, frecuentemente, elementos metonímicos. En otros casos, el punto 
de partida de la construcción de estos multidomain matrix son ya metáforas complejas existentes en nuestra estructura conceptual, entendidas como un complexo conceptual autoconsistente de naturaleza metafórica o metafóricometonímica, creado por medio de la integración de metáforas primarias y metonimias (Gibbs 2005: 117). No obstante, independientemente del tipo de metáforas involucradas, los multidomain matrix que actúan como polos semánticos de construcciones gramaticales son siempre redes complejas de integración conceptual, en el sentido que acabamos de exponer.

Es lo que ocurre también en el caso de las construcciones ditransitivas del kamaiurá que analizaremos a lo largo de las próximas secciones. Como veremos, el polo semántico de estas construcciones está formado por una red de integración conceptual que integra las metáforas subyacentes a la categoría de la TRANSFERENCIA DE OBJETO - constitutiva del significado prototípico de construcciones ditransitivas - con un conjunto de metáforas y metonimias que tienen en el cuerpo humano (o e partes del mismo) su espacio fuente. Las redes complejas metafórico-metonímicas resultantes de dicha integración manifiestan particularidades culturales significativas, tanto respecto a su composición como a las experiencias y actividades que ayudan a conceptuar.

El itinerario que proponemos es el siguiente: tras una breve presentación del pueblo kamaiurá en la próxima sección, presentaremos en la sección 3 la red metafórica que configura la categoría de la TRANSFERENCIA DE OBJETO. La sección 4 la dedicaremos al análisis de las metáforas y metonimias de las construcciones ditransitivas del kamaiurá y de su proceso integración conceptual. Finalizaremos con algunas conclusiones a cerca de las características semánticas y culturales de las redes complejas de integración conceptual analizadas.

\section{El pueblo kamaiurá}

Los kamaiurás son una etnia indígena brasileña localizada en las inmediaciones de la laguna Ypawu, en la zona cultural del Alto Xingú (estado de Mato Grosso). Actualmente cuenta con una población de alrededor de 400 personas distribuidas en dos aldeas principales. La lengua kamaiurá pertenece a la familia del tupí-guaraní, del tronco lingüístico tupí. Entre los estudios lingüístico-culturales dedicados al kamaiurá cabe destacar la Gramática do Kamaiurá, de Lucy Seki (2000) y, más recientemente, la obra $O$ Kwarýp de Kanutari: uma abordagem Linguística e Etnográfica, correspondiente a la tesis de doctorado del lingüista kamaiurá Aisanain Paltu Kamaiura, realizada en el Laboratorio de Lenguas y Literaturas Indigenas (LALLI) de la Universidad de Brasilia y defendida en el Programa de Posgrado en Lingüística de esta misma universidad.

Los datos que sometemos a análisis en el presente estudio fueron gentilmente cedidos por el lingüística kamaiurá Warý Kamaiurá, doctorando en lingüística 
de la Universidad de Brasilia e investigador vinculado al Laboratorio de Lenguas y Literaturas Indigenas (LALLI), y colectados y sistematizados con la ayuda de la Profa. Dra. Ana Suelly Arruda Câmara Cabral, coordinadora del referido laboratorio, a la que agradecemos inmensamente por la posibilidad de desarrollar esta rica experiencia de investigación.

\section{La naturaleza metafórica de la TRANSFERENCIA DE OBJETO}

Básicamente, la categoría de la TRANSFERENCIA DE OBJETO hace referencia a un acto mediante el cual una persona transfiere con sus propias manos un objeto a otra persona que también lo recibe con sus propias manos (Cf. Newman 1996: 1). Para muchos autores esta categoría constituye el polo semántico prototípico de construcciones ditransitivas (Cf. Delbecque/Lamiroy 1996: 90-92; Goldberg 1992: 51; Hollmann 2007: 64; Huelva-Unternbäumen 2010: 119-123; 2015; Newman 1996: 1-21; 2005: 160).

La prototipicidad del acto denotado por esta categoría se sustenta en evidencias y argumentos de peso. Así Newman (1996: 1-4 y 37-38), por ejemplo, señala que el acto de la transferencia de objeto representa un frame básico que actúa como parte constitutiva de una extensa serie de otros frames de carácter más elaborado. Estos frames más complejos elaboran y especifican, cada uno a su manera, el acto de la transferencia de objeto, ubicándolo en el contexto de interacciones socioculturales particulares y en muchos casos altamente ritualizadas. Así, por ejemplo, en el contexto social de una fiesta de cumpleaños (en un ámbito sociocultural determinado) el acto de la transferencia de objeto actúa como una parte constitutiva del frame más extenso - y socialmente más específico y, por lo tanto, también más complejo - denominado REGALAR. En el interior de este frame más complejo los elementos integrantes del acto de la transferencia de objeto sufren especificaciones semánticas determinadas, que se manifiestan, por ejemplo, en una serie de expectativas en relación al comportamiento interactivo de la persona que transfiere el objeto y de la que lo recibe (que incluye, dependiendo de la cultura, la realización de un conjunto de actos de habla ritualizados: ofrecimiento, agradecimiento, atenuación, etc.). Un aspecto que llama especialmente la atención en las observaciones de Newman es que independientemente de los frames complejos en los que el acto de la TRANSFERENCIA DE OBJETO esté inserto e independientemente de las especificaciones semánticas adicionales sufridas en ellos, los elementos constitutivos básicos de este acto permanecen esencialmente los mismos: un agente que transfiere con sus manos un objeto a un receptor que lo recibe también con sus manos. Esta alta presencia de la TRANSFERENCIA DE OBJETO y de los elementos que la integran en diferentes contextos constituye un indicio claro del carácter básico y prototípico de esta forma de transferencia. 
En Huelva Unternbäumen (2010: 5-8) presentamos otro argumento que refuerza este punto de vista. El carácter básico y prototípico de la TRANSFERENCIA DE OBJETO es comprobable a través de una observación importante: los dominios conceptuales que utilizamos para especificar los elementos constitutivos de este tipo de transferencia son usados en muchos casos también para especificar otros tipos de transferencia, mientras que lo contrario no ocurre. Veamos algunos ejemplos:

(1)

(a) Paga oitenta e três reais para o pião.

[Le paga ochenta y tres reales al jornalero]

(b) Eu dou esta garrafa para o Senhor João.

[Doy esta botella al Señor Juan]

(c) O vicinho deu o lote para o filho dele.

[El vecino le regalo la parcela a su hijo.]

(Huelva Unternbäumen 2010: 3)

(2)

(a) Vou mostrar para a imprensa os relatórios de maio.

[Voy a mostrar los informes de mayo a la prensa]

(b) Mostrar para quem quer que seja qual é a nossa realidade.

[Mostrar para quien sea cuál es nuestra realidad]

(Huelva Unternbäumen 2010: 6)

Los ejemplos en (1) (a) y (b) muestran que en muchos casos - aunque no en todos, como se puede apreciar a través de (1) (c) - la TRANSFERENCIA DE CONTROL sobre un objeto conlleva su transferencia física en el dominio espacio-temporal del agente al receptor. Por lo tanto, la configuración del conjunto de dominios conceptuales necesarios para especificar semánticamente los elementos que participan en estos dos casos de TRANSFERENCIA DE CONTROL ha de llevar en cuenta los dominios conceptuales típicos de la TRANSFERENCIA DE OBJETO, como son por ejemplo el dominio conceptual del ESPACIO, del TIEMPO y de la FUERZA. De forma análoga, la TRANSFERENCIA DE PERCEPCIÓN va acompañada frecuentemente de una transferencia del objeto físico percibido, como es el caso de (2) (a) (y a diferencia de (2) (b)). En los casos en que es así, la especificación de la semántica de los elementos que componen este tipo de transferencia ha de recurrir también a los dominios conceptuales propios de la TRANSFERENCIA DE OBJETO. Por el contrario, para especificar una 'simple' transferencia de objeto no es necesario recurrir a dominios conceptuales como el del CONTROL 
o el de la PERCEPCIÓN. Esta asimetría es también una evidencia importante que corrobora el carácter básico y prototípico de la TRANSFERENCIA DE OBJETO.

La alta inserción y recurrencia del acto de la transferencia de objeto y la compleja y variada funcionalidad que desempeña en diferentes situaciones de interacción confieren a este acto un papel central en la experiencia humana. Esta observación se ve corroborada por el hecho de que prácticamente todas las lenguas del mundo poseen algún medio para expresar este tipo de acto. ${ }^{2}$ Desde una perspectiva cognitiva, este estado de cosas nos lleva a concluir que el acto de la transferencia de objeto corresponde a una categoría básica de la conceptualización humana. Newman (1996: 3-4) sugiere que el acto de la transferencia de objeto y su categoría conceptual correspondiente sean considerados una categoría de nivel básico ('basic level category'), en el sentido propuesto por autores como Brown (1965) y Rosch (1973) y sistematizado posteriormente por Lakoff (1987: 31-38, 46-54). Según este último autor, las categorías de nivel básico se caracterizan por poseer las siguientes propiedades: (i) se trata del nivel de las acciones distintivas; (ii) es el nivel que primero se aprende; (iii) las categorías de este nivel son las que poseen mayor relevancia cultural; (iv) las entidades de este nivel (objetos, acciones, etc.) son percibidas de forma holística, como gestalts unitarias (Lakoff 1987: 32-33).

Más recientemente autores como Grady (1997), Lakoff / Johnson (1999) y Gibbs (2005) han postulado un origen y una naturaleza metafóricos de las categorías de nivel básico. Según esta visión, las categorías de este nivel emergen en gran medida como metáforas primarias (o para ser más exactos: como un conjunto de metáforas primarias integradas en una red), en el sentido que mencionamos en la introducción al presente trabajo.

En consonancia con este conjunto de argumentos, analizamos en Huelva Unternbäumen (2015) la TRANSFERENCIA DE OBJETO como una categoría de nivel básico formada por seis metáforas primarias, como se puede apreciar en la figura 1:

\section{Figura 1: metáforas primarias que integran la categoría dela TRANSFERENCIA DE OBJETO}

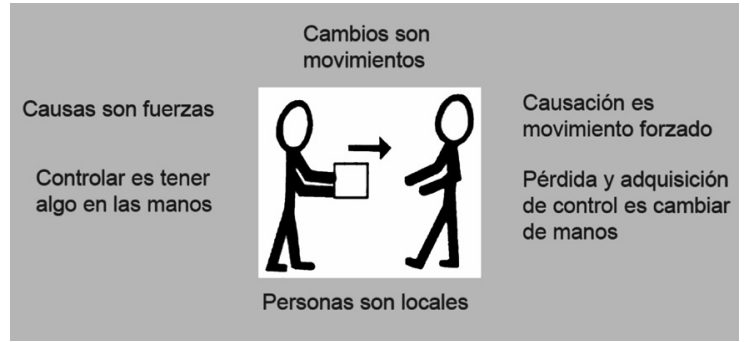

${ }^{2}$ En relación a esta observación y a las posibilidades de expresión en las lenguas del mundo, cf. Malchukov / Haspelmath / Comrie (2010). 
Estas seis metáforas primarias son sometidas a un complejo proceso de integración conceptual operado por el mecanismo de blending (Huelva Unternbäumen 2015: 81-88). Este proceso se lleva a cabo en dos fases diferentes, como se muestra en la figura 2 :

Figura 2: integración conceptual de metáforas primarias.

FASE 1

FASE 2

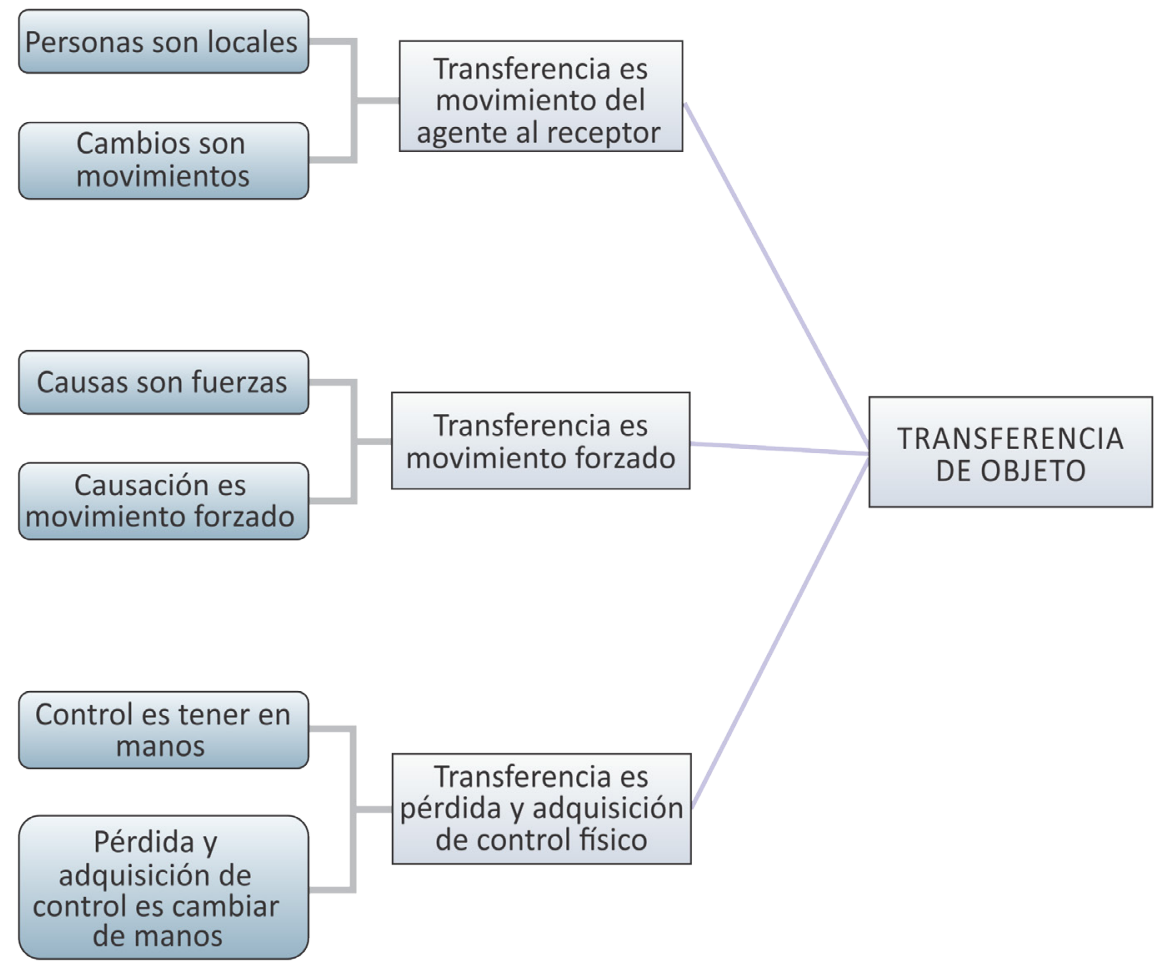

En la primera fase se produce una composición entre pares de metáforas primarias, de la que resulta la creación de las metáforas complejas Transferencia es movimiento del agente al receptor, Transferencia es movimiento forzado y Transferencia es pérdida y adquisición de control fisico. La siguiente observación merece aquí especial atención: mientras que - como ya señalamos en la introducción - las metáforas primarias representan estructuras conceptuales generales, el proceso de composición al cual son sometidas, así como las metáforas complejas que resultan del mismo, son aspectos específicos de la construcción del concepto de la TRANSFERENCIA DE OBJETO. Esto supone que las metáforas primarias en cuestión tan solo forman parte del 
concepto de TRANSFERENCIA DE OBJETO tras la ejecución del proceso de composición, es decir, como elementos constitutivos de la metáfora compleja de la que pasaron a formar parte. La segunda fase consiste en la integración de las tres metáforas complejas mencionadas entre sí dando origen a la categoría metafórica compleja de la TRANSFERENCIA DE OBJETO.

La red metafórica formada atribuye un contenido conceptual concreto a las situaciones en las que percibimos o experimentamos transferencias de objeto. Esto es, mediante el uso de este conjunto de metáforas conceptuamos lo que hasta antes de su utilización era tan solo una escena difusa en la que aparecían dos personas, un objeto, la realización de una serie de acciones, el desplazamiento del objeto, etc., pero que todavía carecía de unidad y particularización conceptuales.

En la figura 3 presentamos la estructura conceptual de la categoría de la TRANSFERENCIA DE OBJETO resultante del proceso de integración metafórica que acabamos de esbozar.

Figura 3: Estructura conceptual de la TRANSFERENCIA DE OBJETO

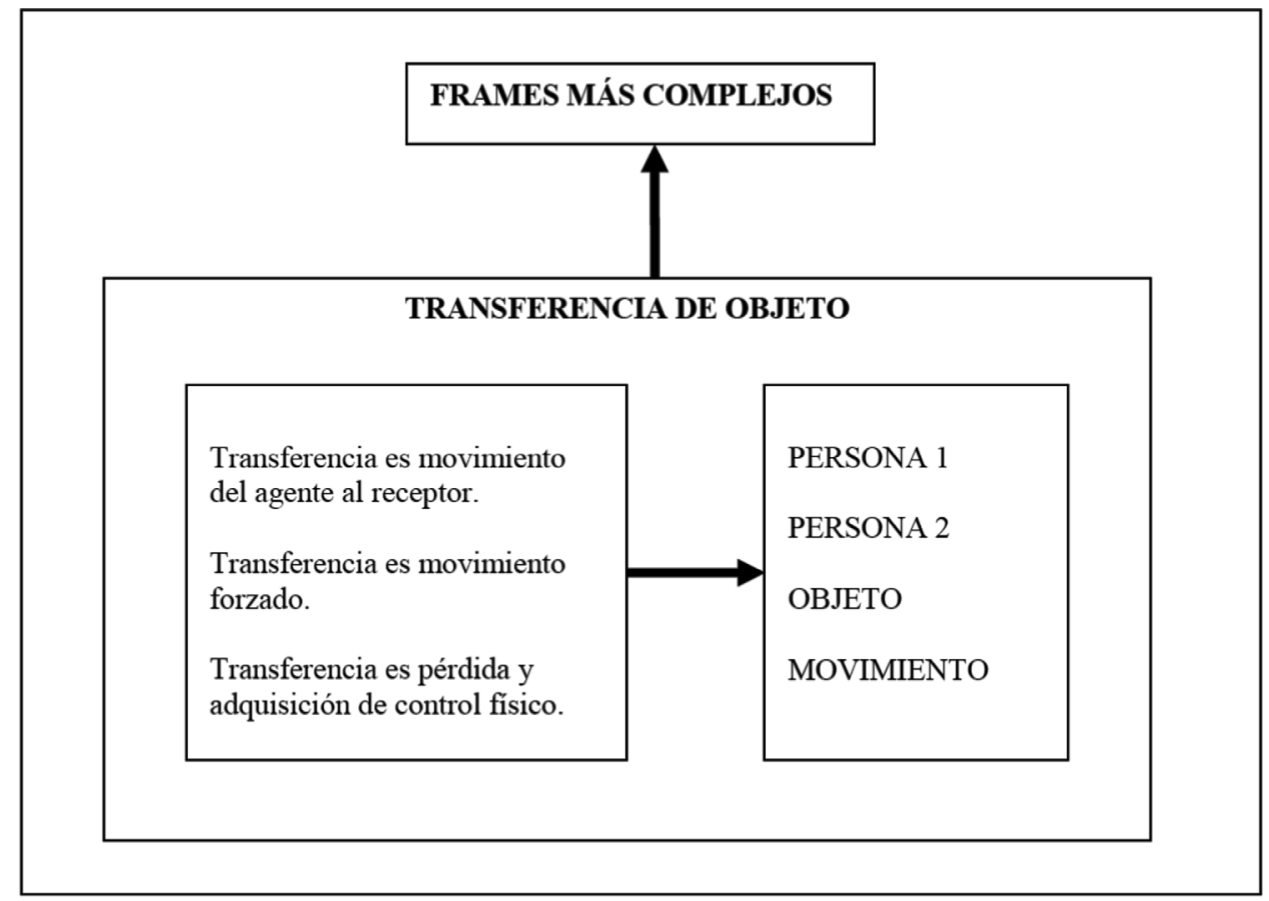

Una vez fijadas en nuestra cognición, las metáforas complejas pueden ser utilizadas como el punto de partida (espacio fuente) para nuevas conceptuaciones. Es lo que ocurre, por ejemplo, con la utilización de la categoría de la TRANSFERENCIA DE OBJETO en la construcción de la categoría de la TRANSFERENCIA DE ACCIÓN, como se puede apreciar en la figura 4: 
Figura 4: espacio fuente y espacio meta en la construcción del concepto de a TRANSFERENCIA DE ACCIÓN.

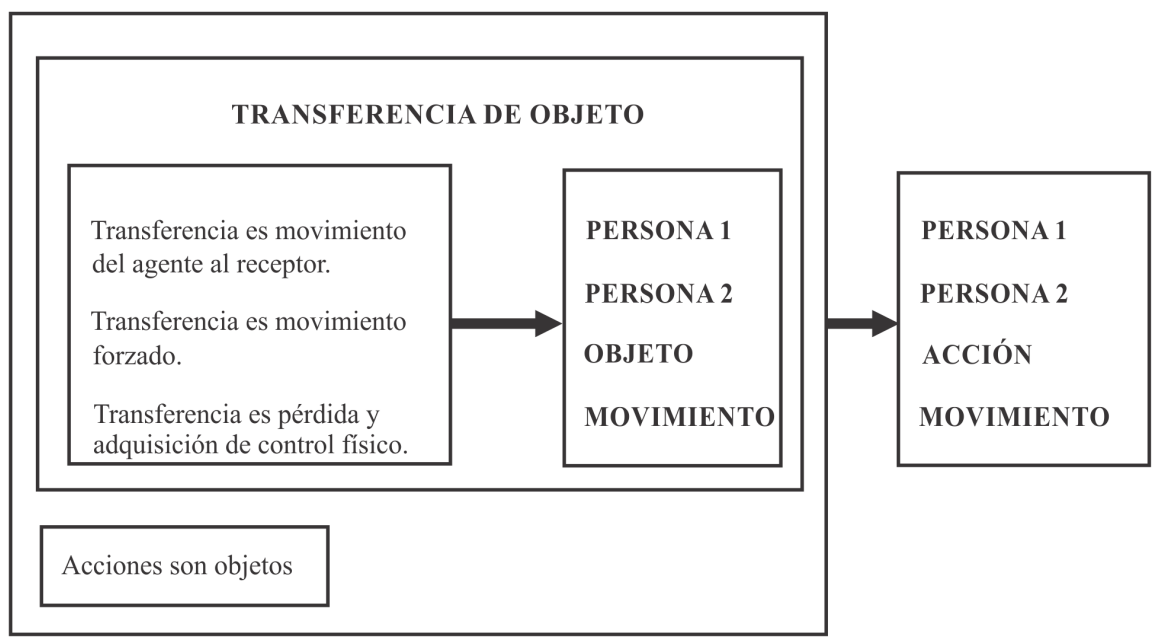

La categoría conceptual de la TRANSFERENCIA DE ACCIÓN corresponde a una red metafórica que se origina a través de la integración de la metáfora compleja de la TRANSFERENCIA DE OBJETO con la metáfora adicional ACCIONES SON OBJETOS. La metáfora compleja resultante de dicha integración constituye el polo semántico de construcciones ditransitivas como dar un beso, un puntapié, un abrazo, etc. a alguien (Palancar 1999; Huelva Unternbäumen 2015: 88-94). Como veremos en la próxima sección, la categoría prototípica de la TRANSFERENCIA DE OBJETO actúa también como punto de partida para la creación del polo semántico de las construcciones ditransitivas del kamaiurá presentes en nuestros datos.

\section{Metáforas en construcciones ditransitivas del kamaiurá con el verbo dar}

En esta sección analizaremos las redes metafórico-metonímicas que forman el polo semántico de algunas construcciones ditransitivas del kamaiurá. Antes de adentrarnos en el análisis en sí, es importante señalar que el kamaiurá dispone de construcciones ditransitivas y de verbos ditransitivos prototípicos (dar, entregar, enviar), lo que no es frecuente en las lenguas conservadoras de la familia tupí-guaraní (tronco tupí). Veamos algunos ejemplos:

(3)

$$
\begin{aligned}
& \text { ne r-emyminome-er-a } \emptyset \text {-ope atsa je, ne r-y'ywa-her-a e-me'eng } \\
& 2 \text { R }{ }^{1} \text {-neto-RETR-ARG } \quad \mathrm{R}^{1} \text {-DAT aten REP } 2 \text { R }{ }^{1} \text {-flecha-RETR-ARG } 2 \text {-dar } \\
& \text { 'de un poco de su flecha a sus nietos' }
\end{aligned}
$$


(4)

$\begin{array}{lll}\text { i-nypyá-het } & \emptyset \text {-y’yw-a } & \text { u-me'eng-e ot } \\ \mathrm{R}^{2} \text {-pedaço } & \mathrm{R}^{2} \text {-flecha-ARG } & \text { 3-dar-GER 3.vir } \\ \text { 'ellos dieron un pedazo de flecha' }\end{array}$

(5)

jumi'ã tõtõa jumi'ã tõtõa $\quad$ etawa-wite i-mono-m

instrumento.de.sopro instrumento.de.sopro cada.um-COM $\mathrm{R}^{2}$-mandar-GER

'ellos (Sol y Luna) le entregaron un instrumento a cada uno'

Tenemos en (3), (4) y (5) construcciones ditransitivas con los verbos dar y entregar en su acepción más prototípica de TRANSFERENCIA DE OBJETO. La existencia en kamaiurá de construcciones ditransitivas con este significado prototípico es de suma importancia para nuestro análisis, puesto que nos legitima a considerar los otros significados que presenta este tipo de construcciones como extensiones metafóricas del significado prototípico. Dicho de una forma más técnica: el polo semántico de las construcciones ditransitivas presentes en nuestro corpus es analizable como una red de integración conceptual que combina las metáforas constitutivas de la categoría de la TRANSFERENCIADE OBJETO con otras metáforas - y metonimias, como veremos -, resultando en estructuras conceptuales de naturaleza metafórico-metonímica de considerable complejidad.

Una característica común a todas las redes metafórico-metonímicas que analizaremos es la presencia del cuerpo humano - o de partes del cuerpo - como el espacio fuente del que se extrae el elemento metafórico y metonímico que particulariza la red conceptual en cuestión, esto es, que le otorga su significado específico. La importancia del cuerpo humano como punto de partida para la construcción de conceptos abstractos codificados gramaticalmente es, como sabemos, un fenómeno general en las lenguas del mundo, no restringible, por lo tanto, al kamaiurá. No obstante, nuestros datos nos permiten afirmar que las construcciones ditransitivas de esta lengua emplean esta estrategia para generar conceptos metafórico-metonímicos en espacios meta distintos a los observables en otras lenguas.

\subsection{Metáfora, metonimia y gramática}

Los datos de los que disponemos reflejan que el verbo dar posee una productividad más limitada en su uso metafórico en kamaiurá que en muchas otras lenguas (Cf. por ejemplo Newman 1996: 133-251). De hecho, todos los enunciados que aparecen en nuestros datos son analizables como variaciones específicas (sub-metáforas) de una misma metáfora general. Veamos algunos ejemplos representativos: 
(6)

$$
\begin{array}{llllll}
\text { ne } & \emptyset \text { - } \phi a ̃-h e r-a & \text { atsã } & \text { e-me'eng } & \text { je } & \emptyset \text {-ope } \\
2 & \mathrm{R}^{1} \text {-dedo-RETR-ARG } & \text { ATEN } & 2 \text {-dar } & 2 & \mathrm{R}^{1} \text {-DAT }
\end{array}
$$

Literal: 'tus exdedos, por favor, dámelos a mi'. Libre: 'quisiera tener tu destreza'

(7)

$$
\begin{array}{llll}
\text { ne } & \emptyset \text {-aikwar-er-a } & \text { atsã } & \text { e-me'eng } \\
2 & \mathrm{R}^{1} \text {-garganta-RETR-ARG } & \text { ATEN } & \text { 2-dar }
\end{array}
$$

Literal: 'dame tu exgarganta'. Libre: 'quisiera cantar tan bien como tú'

(8)

ne r-ea-pyo-het e-me'eng je $\emptyset$-ope

2 R'-olho-astuto-RETR 2-dar $\quad 1 \quad \mathrm{R}^{1}$-DAT

Literal: 'dame tu exojo astuto'. Libre: 'quisiera ser tan listo como tú'

(9)

ne $\emptyset$-akang-er-a e-me'eng je $\emptyset$-ope

$2 \quad \mathrm{R}^{1}$-cabeça-RETR-ARG $\quad$ 2-dar $1 \mathrm{R}^{1}$-DAT

Literal: 'Dame tu excabeza'. Libre: 'quisiera ser tan inteligente como tú'

Tal como mencionamos anteriormente, la conceptuación de las partes del cuerpo humano desempeña un papel fundamental para analizar adecuadamente las metáforas complejas codificadas por construcciones ditransitivas como las que acabamos de ver en los ejemplos de (6) a (9).

Uno de los primeros aspectos que debemos llevar en cuenta a este respecto es que el sustantivo que designa la parte del cuerpo ejerce siempre la función de objeto directo. Es decir, es tratado sintácticamente como el elemento transferido de un agente transmisor a un receptor. En este sentido, podemos afirmar que tal tratamiento sintáctico hace con que se incluya la metáfora PARTES DEL CUERPO SON OBJETOS TRANSFERIBLES como elemento constitutivo de la red metafórica codificada por las construcciones ditransitivas en análisis.

En segundo lugar, es importante observar que, obviamente, no es la parte del cuerpo en sí lo transferido, sino una acción o actividad que realizamos con ella: en (6) ayudar con los dedos, en (7) cantar con la garganta, en (8) percibir (correctamente) con los ojos y en (9) pensar (inteligentemente) con la cabeza. Este aspecto de la conceptuación no tiene una naturaleza metafórica, sino metonímica. Se debe, en concreto, al empleo de la metonimia convencional PARTE DEL CUERPO POR LA FUNCIÓN. Cabe puntualizar que se trata de una metonimia ampliamente documentada en otras lenguas y, por lo tanto, 
no exclusiva del kamaiurá (cf. p. ej. Barcelona 2003: 11-12; Al-Adaileh / Renad 2012; Gibbs / Wilson 2002; Kövecses 2010: 244-245). DEDOS POR AYUDAR, GARGANTA POR CANTAR, OJOS POR PERCIBIR y CABEZA POR PENSAR son versiones específicas de dicha metonimia convencional.

En tercer lugar, debemos llamar la atención sobre la relación conceptual entre la metáfora PARTES DEL CUERPO SON OBJETOS TRANSFERIBLES y la metonimia PARTE DEL CUERPO POR LA FUNCIÓN. Esta relación incluye dos aspectos notables. Por un lado, cabe señalar que partes del cuerpo son, en principio, elementos que poseemos de forma inalienable y que, consecuentemente, no son transferibles en un sentido literal. Descartada esta lectura literal, la inserción de sustantivos que designan partes del cuerpo en una estructura semántica de transferencia desata procesos de inferencia que tornan altamente plausible una reinterpretación de la parte del cuerpo por la función (prototípica) que desempeña. En este sentido, podemos afirmar que la metáfora motiva la inclusión de la metonimia como parte constitutiva de la semántica de las construcciones ditransitivas en análisis.

Por otro lado, la integración conceptual entre ambas desata un proceso de especificación semántica recíproca. La metonimia especifica al concepto de PARTES DEL CUERPO, indicándonos en qué sentido debemos entender que son objetos transferibles. Con ello, la metáfora PARTES DEL CUERPO SON OBJETOS TRANSFERIBLES se particulariza en LA FUNCIÓN DE UNA PARTE DEL CUERPO ES UN OBJETO TRANSFERIBLE. Al mismo tiempo es importante percatarse que la metonimia PARTE DEL CUERPO POR LA FUNCIÓN adquiere también una semántica más específica cuando la integramos con la referida metáfora - y de un modo más general, cuando forma parte de la compleja red metafórica que subyace a la categoría de la TRANSFERENCIA en enunciados como los presentados de (6) a (9). En el contexto de estos enunciados, la parte del cuerpo en cuestión aparece como algo que se desea tener, algo que se desea que pase del otro (oyente) a mí (hablante). Y como, generalmente, uno no quiere cosas malas para sí, sino más bien buenas, la función prototípica representada por cada una de las partes del cuerpo nombradas recibe una valoración positiva: los dedos están por la destreza en (6), la garganta por el buen cante en (7), los ojos por la astucia en (8) y la cabeza por la inteligencia en (9). ${ }^{3}$ En suma, no es la función del órgano sino su desempeño lo que está en primer plano. La figura 5 muestra esquemáticamente esta especificación semántica recíproca entre metáfora y metonimia:

\footnotetext{
${ }^{3}$ Véase Barcelona (2003:11-12) para una particularización de OÍDOS POR OÍR > OÍDOS POR ATENCIÓN en contextos metafóricos.
} 
Figura 5: integración conceptual entre metáfora y metonimia

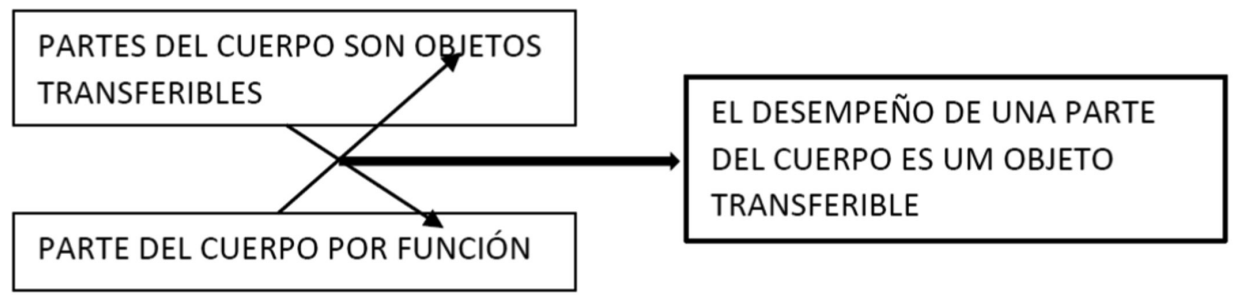

Si nos preguntamos por las particularidades de kamaiurá, debemos hacer algunas ponderaciones. En primer lugar-y como ya mencionamos anteriormente - cabe señalar que metonimia PARTE DEL CUERPO POR LA FUNCIÓN no es una exclusividad de la referida lengua, como se puede ver a partir de los ejemplos siguientes del español y del portugués:

Dar uma mão / mãozinha (= ajudar).

Arrimar el hombro (= ajudar).

Meter o nariz em algo (=entrometerse).

Meter o braço em alguém (=pegar).

Dar ouvido a alguém (=prestar atención, llevar en cuenta la opinión de otra persona).

Dar língua / dedo (=burla, provocación).

Además, tampoco debemos considerar como algo genuino del kamaiurá la transformación de esta metáfora en la versión más específica PARTE DEL CUERPO POR EL DESEMPEÑO:

(11)

Tener buena mano.

Tener ojo clínico / ojos expertos.

Tener el cráneo seco / cabeza de chorlito.

Ser (un) cráneo.

El uso de la parte del cuerpo por el desempeño parece estar motivado por contextos (frames) en los que se pretende expresar una valoración, sea positiva (tener buena mano/ojo clínico, ser un cráneo) o incluso negativa (tener el cráneo seco/ cabeza de chorlito).

Ahora bien, como dijimos anteriormente, en el caso de los enunciados del kamaiurá en análisis, la valoración positiva está motivada directamente por la semántica de las construcciones ditransitivas. En efecto, lo que parece ser una peculiaridad de esta lengua es la inserción de la metonimia PARTE DEL 
CUERPO POR FUNCIÓN en la red metafórica típica de la categoría de la TRANSFERENCIA. No tenemos constancia de la existencia de este tipo de integración conceptual en otras lenguas.

Un cuarto y último aspecto relativo a la conceptualización de las partes del cuerpo en las construcciones ditransitivas de los enunciados en (6), (7), (8) y (9) que merece especial atención es la función desempeñada por la categoría gramatical del retrospectivo (RETR). Como se puede apreciar en los referidos enunciados, esta categoría se realiza directamente como marca del sustantivo que designa la respectiva parte del cuerpo. Su aporte semántico, sin embargo, transciende el escopo inmediato del sustantivo e incluye el enunciado como un todo. Seki analiza el retrospectivo como marca (sufijo) de tiempo (Seki 2000: 305-306). En este punto, cabe puntualizar que el kamaiurá no expresa la categoría del tiempo mediante la flexión verbal, sino por medio de lexemas o expresiones temporales y sufijos nominales (Seki 2000: 136). En cuanto a su aporte semántico, observa esta autora que el retrospectivo hace referencia a un estado que será pasado en el futuro, pudiendo ser parafraseado como 'lo que dejará de ser', 'lo que habrá sido' o 'el futuro ex', en enunciados como en (12):

je $=\mathrm{r}-\mathrm{emi}$ ' $\mathrm{u}-\mathrm{her}-\mathrm{am}$

$1 \mathrm{sg}=$ REL-comida-RETR-ATR

Literal: lo que dejará de ser mi comida; Libre: lo que habrá sido mi ex comida. (Seki 2000: 306)

Añade Seki que el retrospectivo es usado frecuentemente con términos que denotan partes del cuerpo humano y animal y, de forma más general, con referentes inalienables, "cuando los términos se refieren a las partes separadas de su respectivo todo o de su poseedor o a relaciones de parentesco que dejaron de existir" (Seki 2000: 306), como se observa en los ejemplos siguientes:

-aĩ-het

(ex diente)

-emireko-het

(ex esposa)

(Seki 2000: 306)

Finalmente, Seki (2000: 306) apunta además que el retrospectivo acompaña a términos que designan objetos que pertenecieron a personas ya fallecidas y también a los que denotan señales dejadas por partes del cuerpo, como se aprecia en los siguientes enunciados: 
(14)

$\begin{array}{lll}\text { ini-her-a } & \text { a -pahwa-pahwat } & \text { t-apy }-\mathrm{m} \\ \text { red-RETR-N } & \text { 1sg-enrollar-red } & 3 \text {-quemar-G } \\ \text { Enrollé la red [que era de ellos] para quemarla }\end{array}$

(Seki 2000: 306)

je $\emptyset$-pa-het o-'up

1 R'-mano-RETR 3.CORR-estar.

Literal: 'mi ex-mano está tendida'; Libre: la huella de mi mano

Ahora bien, si comparamos los ejemplos analizados por Seki y los enunciados en (6) a (9), se manifiestan dos diferencias importantes. En primer lugar, los sustantivos en (6) a (9) se refieren a partes del cuerpo que no se han separado de su todo, o sea, del cuerpo del oyente. Además, su 'poseedor' todavía está vivo. Por lo tanto, es necesario buscar otro referente, más allá de la parte del cuerpo en su calidad de objeto físico, para que los enunciados tengan sentido. En segundo lugar, es importante observar que los referentes de los sustantivos sufijados por el retrospectivo en (6) a (9) forman parte de enunciados que expresan transferencia, correspondiendo, en concreto, al objeto a ser transferido. Obsérvese, asimismo, que mediante estos enunciados el hablante realiza un acto de habla petitivo, atenuado por el uso del atenuador atsã (por favor). En síntesis, el punto de partida para analizar la construcción conceptual concreta del referente de los mencionados sustantivos está constituido por enunciados con un significado que podemos parafrasear como 'dame por favor lo que será/ llegará a ser tu ex cabeza'. A continuación, proponemos un análisis de esta construcción conceptual basado en la Teoría de la Integración Conceptual (Fauconnier 1997; Fauconnier / Turner 2002).

\subsection{Integración conceptual}

En una primera tentativa de descripción, podemos afirmar que el retrospectivo crea un espacio mental (en el sentido de Fauconnier 1997) de lo imaginado y, por lo tanto, de lo irreal, en el que sitúa una especie de duplicación de la parte del cuerpo. Es esta parte duplicada la que constituye el objeto de la transferencia deseada, de tal modo que, una vez concluida, habrá pasado a mi posesión, convirtiéndose en tu ex parte del cuerpo (y, metonímicamente, en tu ex desempeño). De esta forma, la retrospección está situada en el futuro, crea un pasado del futuro en el que yo desearía que la 'duplicación de tu cabeza' (metonímicamente, 'la duplicación de tu inteligencia') pasase a ser mía.

Como ya mencionado, a pesar de que el retrospectivo tenga una incidencia gramatical directa en el sustantivo que modifica, la creación de un espacio de lo irreal repercute en el significado global del enunciado. ${ }^{4}$ Pedir a mi interlocutor

${ }^{4}$ Sobre la construcción local d espacios mentales y su repercusión global en la semántica de enunciados véase Fauconnier 1997: 118-120). 
que me dé algo que no existe y que, por lo tanto, no puede ser objeto de ningún acto de transferencia, desata procesos de inferencia que llevan a la búsqueda de interpretaciones alternativas. Según nuestro colaborador Warý Kamaiurá, los enunciados que contienen este tipo de construcciones ditransitivas poseen un carácter desiderativo. Expresan un deseo remoto, irrealizable y, por lo tanto, hipotético de poseer la misma habilidad, capacidad o destreza que posee el interlocutor. La utilización del mismo tipo de enunciado con sustantivos que designan distintas partes del cuerpo nos lleva a creer que la lectura desiderativa constituye un aspecto convencionalizado del mismo.

En este sentido, el retrospectivo manifiesta el mismo efecto sobre el referente de un sustantivo que otros space builders (Fauconnier 1997: 40), a saber, sitúa el referente en un determinado espacio mental: en el espacio mental de lo real, de lo ficticio, de lo hipotético, de lo deseado, etc. En nuestro caso concreto, se comporta de una forma análoga al imperfecto de subjuntivo o condicional en construcciones como las siguientes:

$¡$ ¡Y quisiera yo tener tu inteligencia!

¡Cómo me gustaría tener tu corazón y perdonar siempre a todos!

En (12) se produce el mismo efecto de duplicación de los referentes de inteligencia y corazón en espacios hipotético-desiderativos. La posesión expresada por el verbo tener opera sobre estos referentes y no sobre los referentes en el espacio de lo real. La lectura final de los enunciados es la misma que hemos atribuido a los ejemplos del kamaiurá: 'me gustaría tener una inteligencia y una bondad como la tuyas' (y no exactamente las tuyas).

Tras analizar la conceptuación de las partes del cuerpo, estamos ya en condiciones de describir el proceso de integración conceptual que da origen a la red metafórica correspondiente al polo semántico de las construcciones ditransitivas en su totalidad. Por motivos de simplificación, se expondrá este proceso en dos pasos. En el primero, se describirá la integración entre la categoría de la TRANSFERENCIA DE OBJETO y la metáfora DESEMPEÑO ES UN OBJETO TRANSFERIBLE, mientras que en el segundo nuestra atención se centrará en la conceptuación de la transferencia en el espacio hipotéticodesiderativo al que nos acabamos de referir.

La figura 6 representa el proceso de integración entre la categoría metafórica de la TRANSFERENCIA DE OBJETO y la metáfora compleja DESEMPEÑO ES UN OBJETO TRANSFERIBLE (la representación prescinde de una reproducción integral de sus estructuras interna): 
Figura 6: integración conceptual entre la categoría de la TRANSFERENCIA DE OBJETO y la metáfora EL DESEMPEÑO DE UNA PARTE DEL CUERPO ES UN OBJETO TRANSFERIBLE.

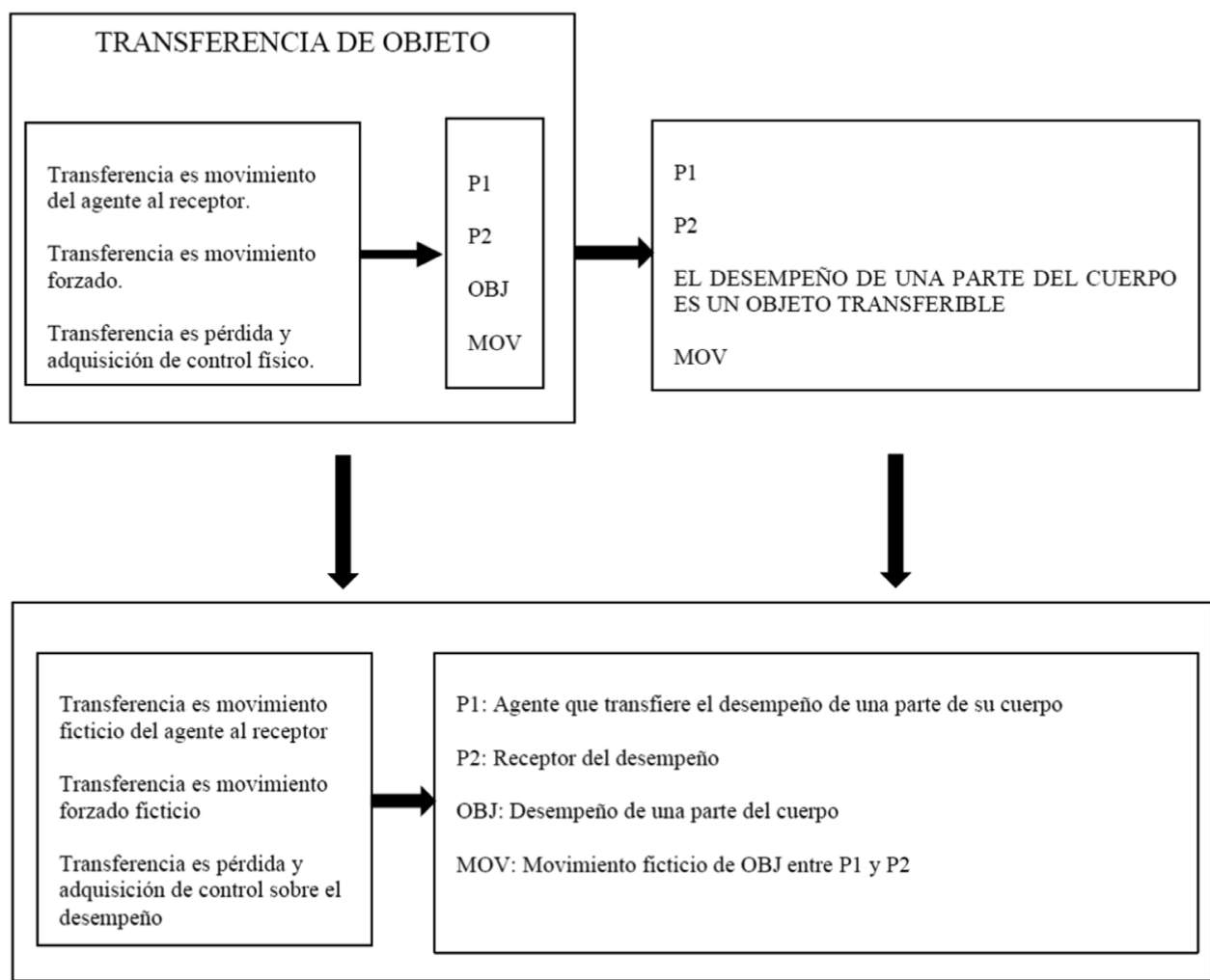

Tal como ocurre en todo proceso de integración conceptual, en el blend emergen características que no existían en ninguno de los espacios de input (Fauconnier/Turner 2002: 42-57). Sin querer ni poder entrar mucho en pormenores, cabe señalar que, en el caso de la integración representada en la figura 6 , sobresale la pérdida de la naturaleza física de la transferencia y su substitución por una transferencia de carácter ficticio. ${ }^{5}$ Este reemplazo modifica la estructura conceptual de las tres metáforas provenientes de la categoría de la TRANSFERENCIA DE OBJETO y, al mismo tiempo, especifica la semántica de los cuatro elementos esenciales involucrados en el acto de la transferencia: las dos personas ( $\mathrm{P} 1$ y P2), el objeto transferido y el movimiento del mismo de P1 a P2.

En la figura 7 se muestra el proceso de integración que da origen a la conceptuación de la transferencia hipotético-desiderativa del desempeño de una parte del cuerpo.

${ }^{5}$ Para el concepto de la fictividad y su codificación gramatical véase Langacker (2008: 524-535). 
Figura 7 -: Integración conceptual de la transferencia hipotético-desiderativa del desempeño. Los corchetes con líneas sólidas señalan las correspondencias entre elementos de los intputs, mientras que los punteados indican las proyecciones al blend.

INPUT 1 (espacio de lo real)

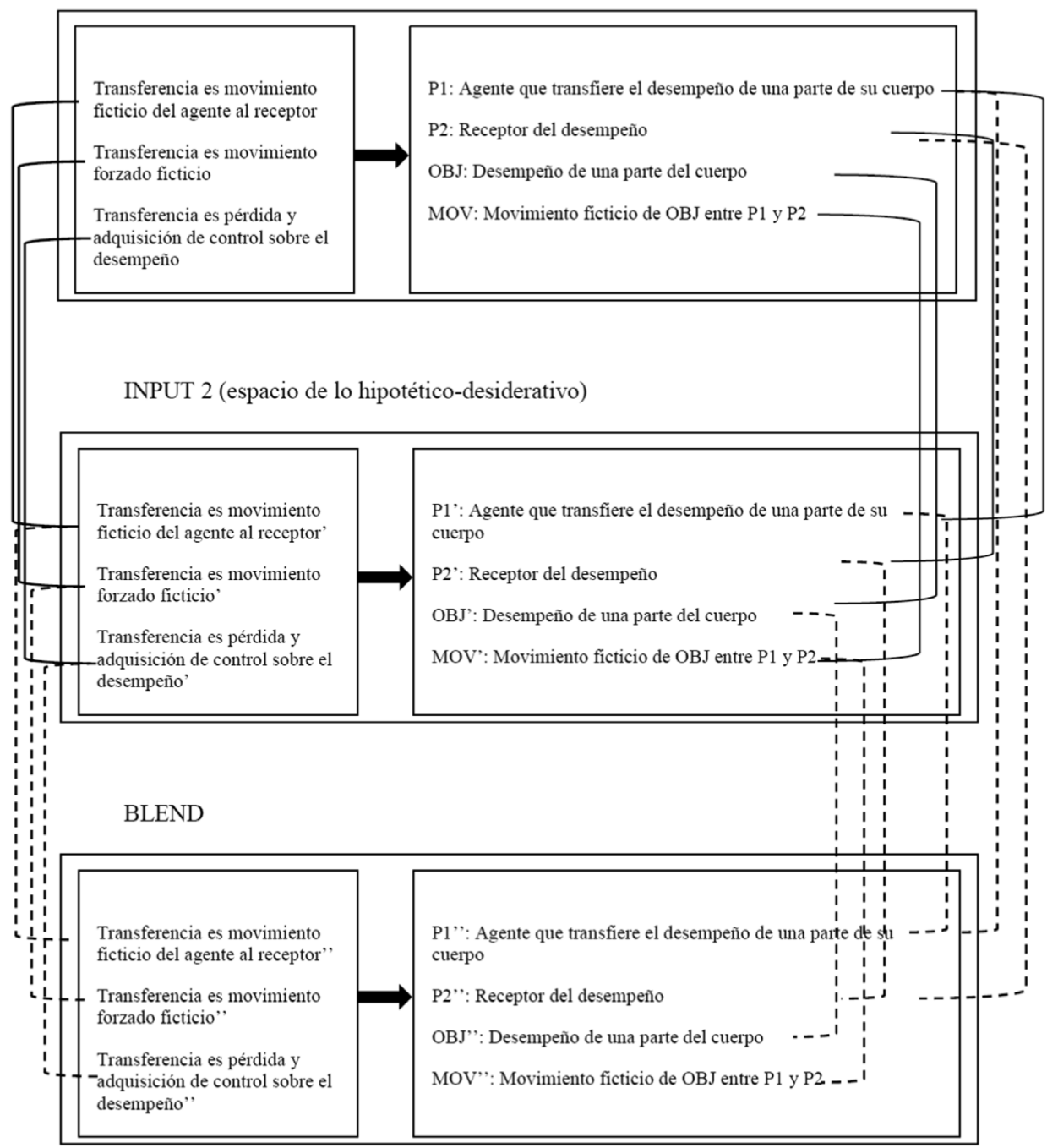

Como se mencionó anteriormente, el retrospectivo actúa como un space builder que crea un espacio de lo hipotético-desiderativo en el que se ubica una duplicación (irreal) del desempeño de la parte del cuerpo del oyente. El proceso de transferencia (deseado) se refiere a esta duplicación y no al desempeño real. Es oportuno mencionar que, al igual que la parte del cuerpo correspondiente, el desempeño representa también un referente inalienable y, por lo tanto, 
intransferible en el espacio de lo real. Este espacio de lo hipotético-desiderativo (INPUT 2) es integrado conceptualmente con el espacio de lo real (INPUT 1). Como sucede en todos los procesos de blending, la proyección de elementos de los espacios del input al blend es selectiva (Fauconnier/Turner 2002: 4748). Los participantes del proceso de transferencia (P1 y P2, el agente y el receptor respectivamente) son proyectados de ambos espacios del input, puesto que sus identidades permanecen inalteradas en ellos y en el blend. El resto de los elementos, por el contrario, son proyectados tan sólo a partir del INPUT 2. Eso se debe, por una parte, a que el proceso de transferencia del desempeño no se lleva a cabo (o mejor: no se desea que se lleve a cabo) en el mundo de lo real, sino de lo deseado. Consiguientemente, las tres metáforas complejas que configuran conceptualmente a la categoría de la transferencia se proyectan sólo desde el INPUT 2. Por otra parte - y por razones análogas -, el objeto de la transferencia y su movimiento entre $\mathrm{P} 1$ y $\mathrm{P} 2$ también son proyectados a partir del INPUT 2 y no del espacio de lo real. Lo que se desea que sea transferido es la duplicación hipotética del desempeño y no el desempeño original.

En el blend surgen estructuras emergentes no existentes en los espacios de input. Estas estructuras resultan, por una parte, de un proceso de composición conceptual (Fauconnier/Turner 2002: 48) que vincula elementos que en los inputs no estaban en relación. Así, en el blend de la figura 7, un agente transmisor (P1) y un receptor (P2) reales (!) son relacionados con un proceso ficticio de transferencia que afecta a un objeto constituido por la duplicación imaginaria del desempeño de una parte del cuerpo de P2. Esta configuración de elementos en su conjunto emerge tan sólo en el blend.

Por otra parte, el blend, una vez establecido, puede reclutar - total o parcialmente - frames pertenecientes a nuestro conocimiento general como miembros de una determinada cultura. Esta operación es denominada compleción (Fauconnier/Turner 2002: 48). En el caso en análisis, el blend recluta (y se insiere en) el frame de la actividad comunicativa específica de 'expresar un deseo hipotético'. Como mencionamos anteriormente, esta parece ser una función comunicativa convencionalizada de las construcciones ditransitivas del kamaiurá con sustantivos en función de objeto directo que denotan partes del cuerpo y se encuentran modificados por un retrospectivo. Al mismo tiempo, mediante enunciados con este tipo de construcciones, el hablante profiere un elogio, al destacar un desempeño excepcional del oyente (su destreza, inteligencia, cante, etc.).

\section{Consideraciones finales}

La red metafórico-metonímica que hemos analizado en este trabajo constituye uno de los polos semánticos posibles de las construcciones ditransitivas del kamaiurá. No tengo conocimiento de que la literatura especializada en metáfora 
y metonimia dé constancia de una estructura con características similares en otra lengua. Aunque trascienda el objetivo de nuestra investigación, creemos pertinente mencionar que las construcciones ditransitivas con dar de esta lengua parecen diferenciarse significativamente, con respecto a su semántica, de lo que conocemos de muchas lenguas europeas. Así, los datos de nuestro corpus no reflejan, por ejemplo, ningún caso de transferencia de acción física (dar un abrazo, dar un puñetazo, dar un beso, etc.), ni de acción comunicativa (dar un consejo, una advertencia, una orden, etc.). Los datos de Seki (2000) y Aisanain Paltu Kamaiurá (2015) corroboran esta observación. En contrapartida, sin embargo, se observa un conjunto significativo de redes metafórico-metonímicas generadas por construcciones ditransitivas con el verbo mono (enviar, mandar) que poseen una semántica muy particular: enviar el ojo a alguien (acordarse de alguien), enviar el brazo a alguien (abrazar), etc. (Huelva Unternbäumen, en preparación).

En nuestro análisis ha merecido un destaque especial la metonimia PARTE DEL CUERPO POR FUNCIÓN y su transformación en PARTE DEL CUERPO POR DESEMPEÑO. Caben aquí, como complemento a su análisis, algunas observaciones más generales. En primer lugar, esta metonimia no es una particularidad del kamaiurá, puesto que está documentada, como señalamos, en otras lenguas. Sí lo es, empero, su inserción en una semántica general de transferencia, esto es, su 'objetificación' metafórica como algo transferible de una persona a otra. No me constan casos semejantes en otras lenguas analizadas. En segundo lugar, es importante hacer mención a la alta complejidad que manifiesta la relación conceptual entre la metáfora y la metonimia resultante de esta inserción. Destaca, antes de todo, que la inserción de la metonimia tiene lugar a partir de un proceso inferencial desencadenado por el uso de un sustantivo que denota una parte del cuerpo en el contexto de una red metafórica que conceptúa transferencia. En este sentido, podemos afirmar que tenemos una motivación metafórica para el uso de la referida metonimia. Otro aspecto que requiere una mayor reflexión es el proceso de integración en sí. Como vimos, la integración conceptual de la metonimia se inicia a través de su vínculo con la metáfora PARTES DEL CUERPO SON OBJETOS TRANSFERIBLES. De la integración conceptual entre estos dos elementos emerge la metáfora EL DESEMPEÑO DE UNA PARTE DEL CUERPO ES UN OBJETO TRANSFERIBLE. Esta metáfora con substancia metonímica ejerce una dominancia clara en el proceso global de integración conceptual, puesto que determina la naturaleza del objeto a ser transferido y, con ello, caracteriza el proceso de transferencia en su totalidad. Podemos afirmar, pues, que el componente metonímico manifiesta un alto poder de propagación en la red de integración conceptual representada en la figura 7.

Por último, quisiéramos fijar la atención en el papel de la gramática y, en particular, de la categoría del retrospectivo. Las construcciones ditransitivas 
del kamaiurá con el verbo dar, un sustantivo que denota una parte del cuerpo, la presencia del retrospectivo y, frecuentemente también del atenuante atsãa, deben ser consideradas como un tipo específico de construcción - en el sentido de la Gramática de Construcciones (Goldberg 1995; Croft 2001) -, por ser constatable un emparejamiento estable (convencionalizado) entre la forma de estas construcciones y su significado. Su significado reside en la construcción de un polo semántico configurado por una red conceptual metafórico-metonímica como fue descrita en la sección 4 y representada gráficamente en la figura 7. El retrospectivo es, sin duda, la pieza clave en la construcción de dicha red, pues su uso nos induce a crear el espacio de lo hipotético-desiderativo, esencial para semántica global de la construcción.

\section{Bibliografía}

Al-Adaileh, Bilal and Renad Abbadi. 2012. The pragmatic implications of metonymical body-based idioms in Jordanian Arabic, Argumentum 8:73-91.

Barcelona, Antonio. 2003. Introduction: The Cognitive Theory of Metaphor and Metonymy, in: Antonio Barcelona (Ed), Metaphor and Metonymy at the Crossroads. Berlin/New York: Mouton de Gruyter, pp. 1-28.

Brown, Roger. 1965. Social psychology. New York: Free Press.

Croft, William. 2001. Radical Construction Grammar. Syntactic Theory in Typological Perspective. Oxford: OUP.

Delbecque, Nicole, and Béatrice Lamiroy. 1996. Towards a typology of the Spanish dative. In W. Van Belle and W. Van Langendonck (Eds.), The dative, vol. 1. Amsterdam \& Philadelphia: John Benjamins, pp. 71-117.

Fauconnier, Gilles. 1997. Mappings in Language and Thought. Cambridge: Cambridge University Press.

Fauconnier, Gilles, and Mark Turner. 2002. The way we think: conceptual blending and the mind's hidden complexities. New York: Basic Books.

Gibbs, Raymond. 2005. Embodiment and Cognitive Science. Cambridge: CUP.

Gibbs, Raymond W. and Nicole L. Wilson. 2002. Bodily Action and Metaphorical Meaning. Style 36(3):524-541.

Goldberg, Adele. E. 1992. The inherent semantics of argument structure: the case of the English ditransitive construction. Cognitive Linguistics 3:37-74.

. 1995. Constructions: a Construction Grammar approach to argument structure. Chicago: University of Chicago Press.

Grady, Joseph E. 1997. Foundations of meaning: primary metaphors and primary scenes. Unpublished $\mathrm{PhD}$ dissertation. University of Berkeley.

Hollmann, Willem. 2007. From language-specific constraints to implicational universals: a cognitive-typological view of the dative alternation. Functions of Language 14 (1):57-78. 
Huelva Unternbäumen, Enrique. 2010. The complex domain matrix of ditransitive constructions. Constructions 1, 11 May 2010, online: <http://elanguage.net/ journals/constructions/article/view/749>.

Huelva Unternbäumen, Enrique. 2015. From primary metaphors to the complex semantic pole of grammatical constructions. Language and Cognition 7:68-97.

Kövecses, Zoltan. 2005. Metaphor in Culture. Universality and Variation. Cambridge: CUP.

Kövecses, Zoltan. 2010. Metaphor. A Practical Introduction. Oxford: OUP.

Lakoff, George. 1987. Women, fire, and dangerous things: what categories reveal about the mind. Chicago \& London: University of Chicago Press.

Lakoff, George, and Mark Johnson. 1999. Philosophy in the flesh: the embodied mind and its challenge to Western thought. New York: Basic Books.

Langacker, Ronald W. 2008. Cognitive Grammar: a basic introduction. Oxford: Oxford University Press.

Malchukov, Andrej; Martin Haspelmath and Bernard Comrie (Eds.) 2010. Studies in ditransitive constructions: a comparative Handbook. Berlin \& New York: de Gruyter.

Newman, John. 1996. Give: a cognitive linguistic study. Berlin \& New York: Mouton de Gruyter.

Palancar, Enrique. 1999. What do we give in Spanish when we hit? A constructionist account of hitting expressions. Cognitive Linguistics 10 (1): 57-91.

Paltu Kamaiurá, Aisanain. 2015. O Kwarýp de Kanutari: uma abordagem linguística e etnográfica. Unpublished $\mathrm{PhD}$ dissertation. University of Brasília.

Rosch, Eleanor. 1973. Natural categories. Cognitive Psychology 4:328-350.

Seki, Lucy. 2000. Gramática do Kamaiurá. Língua Tupi-Guarani do Alto Xingu. Campinas: Editora da Unicamp.

Data recebimento: $17 / 05 / 2015$

Data aceite: $15 / 07 / 2015$ 